\title{
PEMETAAN KERAWANAN KEBAKARAN MENGGUNAKAN PENDEKATAN INTEGRASI PENGINDERAAN JAUH DAN PERSEPSI MASYARAKAT DI KECAMATAN TAMBORA JAKARTA BARAT
}

\author{
Siti Dahlia, Wira Fazri Rosyidin, Aditya Ramadhan, Haryadi, Khoirul Anwar, \\ Dimas Ersantyo, Rahmad Nur Setiawan, M. Aji Sadewo, Asa Alvi Zahroh \\ Pendidikan Geografi, Universitas Muhammadiyah Prof. DR. Hamka, Jakarta Timur \\ e-mail: sitidahlia@uhamka.ac.id
}

\begin{abstract}
Abstrak
Kecamatan Tambora Jakarta Barat merupakan salah satu wilayah di DKI Jakarta yang memiliki tingkat kepadatan penduduk tinggi, kondisi tersebut mengakibatkan wilayah penelitian rawan terhadap kebakaran. Untuk itu, tujuan penelitian yaitu untuk membuat peta kerawanan kebakaran menggunakan pendekatan integrasi penginderaan jauh dan persepsi masyarakat di Kecamatan Tambora Provinsi DKI Jakarta. Pembuatan peta kerawanan kebakaran merupakan salah satu upaya mitigasi nonstruktural, sehingga wilayah penelitian teridentifikasi tingkat zonasi kerawanan kebakaran untuk bahan acuan kebijakan penurunan tingkat risiko. Metode pengumpulan data yang digunakan yaitu interpretasi, dokumentasi, observasi, dan wawancara. Metode analisis yang digunakan yaitu kualitatif dan kuantitatif. Analisis kualitatif yang digunakan yaitu menginterpretasi data citra Quickbird berdasarkan unsur-unsur interpretasi dan mendeskripsikan temuan kondisi di lapangan. Analisis kuantitatif yang digunakan yaitu menggunakan metode pembobotan dan skoring. Hasil penelitian yaitu wilayah Kecamatan Tambora mayoritas merupakan area kerawanan kebakaran tingkat tinggi seluas $258 \mathrm{Ha}$, tingkat kerawanan sedang seluas $113 \mathrm{Ha}$, dan tingkat kerawanan rendah seluas $137 \mathrm{Ha}$. Kelurahan dengan tingkat kerawanan kebakaran tinggi yaitu Kelurahan Pekajon, Angke, Krendeng, Duri Utara, dan Kalianyer. Kelurahan dengan tingkat kerawanan kebakaran sedang yaitu Tanah Sereal, Jembatan Besi, dan Duri Selatan. Kelurahan dengan tingkat kerawanan kebakaran rendah yaitu Roa Malaka, Jembatan Lima, dan Tambora.
\end{abstract}

Kata kunci: kerawanan kebakaran, penginderaan jauh, persepsi masyarakat, dan Kecamatan Tambora

\begin{abstract}
Tambora Distric West Jakarta is part of area in Jakarta Province which has high population density. That condition caused research area has high frequency by fire incident. Based on that, the aim of research is maping of fire susceptibility using remote sensing and community perception approach in Tambora Distric West Jakarta. Maping of fire susceptibility area is important as effort non structural mitigation acction to reduce risk. Methods to collect data ware Interpretation, observation, dokumentation, and interviews. The analysis data was used by qualitative and quantitative methods. Qualitative analysis used for interpretation Quick Bird Satellite Imagery and also describe filed conditions. Furthermore, Quantitative analysis used for weight and skoring analysis. The result of research showed that majority Tambora Distric has high fire susceptibility area $(258 \mathrm{Ha})$, medium fire susceptibility area $(113 \mathrm{Ha})$, and low fire susceptibility area (137 Ha). Village has high fire susceptibility namely: Pekajon, Angke, Krendeng, Duri Utara, and Kalianyer. Village has medium fire susceptibility namely: Tanah Sereal, Jembatan Besi, and Duri Selatan. Village has low fire susceptibility namely: Roa Malaka, Jembatan Lima, and Tambora.
\end{abstract}


Key words: fire susceptibility, remote sensing, community perseptions, and Tambora Distric

\section{PENDAHULUAN}

Adanya proses perkembangan kota-kota besar di Indonesia terutama kota metropolitan yang relatif cepat baik perkembangan secara fisik maupun non fisik. Hal ini disebabkan karena daerah kota merupakan pusat segala jenis aktivitas yang menawarkan berbagai fasilitas pendukung kehidupan baik dari mulai fasilitas pendidikan, kesehatan, perkantoran maupun kawasan perindustrian yang lebih baik daripada yang ada di daerah. Keberadaan kota yang menawarkan berbagai fasilitas sarana dan prasarana yang lebih baik ini, menjadi salah satu daya tarik tersendiri bagi orang-orang untuk mengadakan migrasi ke kota. Besarnya laju urbanisasi serta pertumbuhan penduduk kota itu sendiri menimbulkan masalah ketersediaan ruang untuk permukiman yang semakin terbatas, terutama kawasan perumahan untuk golongan ekonomi menengah ke bawah (Yanuar, 2012).

Kebakaran adalah salah satu bencana yang seringkali terjadi di perkotaan, kebakaran merupakan bahaya yang mengancam keselamatan jiwa manusia atau harta benda jika nyala api yang tidak terkendali. Kebakaran terjadi sebagai reaksi segitiga api (fire triangle) yaitu reaksi dari bahan yang mudah terbakar (fuel) oksigen dan panas (heat). Bencana kebakaran di perkotaan tidak dapat diperkirakan atau diprediksikan kapan terjadinya dan penyebabnya, yang dapat dilakukan adalah dengan persiapan dan peringatan dini. Kejadian kebakaran di Indonesia tercatat cukup tinggi, khususnya di permukiman masyarakat menengah kebawah, karena mempunyai kepadatan tinggi (Januandari, Rachmawati, \& Sufianto, 2017). Identifikasi bahaya kebakaran merupakan suatu proses mengidentifikasi bahwa adanya potensi bahaya kebakaran dan mengenali karakteristinya (Xin \& Huang, 2013).

Provinsi DKI Jakarta sebagai Ibu Kota Negara Republik Indonesia, merupakan area megapolitan maupun pusat pertumbuhan dan pembangunan memiliki permasalahan kebencanaan yang kompleks. Kebakaran permukiman merupakan bencana yang menjadi ancaman kedua bagi provinsi DKI Jakarta setelah bencana banjir (Paripurno et al., 2012). Provinsi DKI Jakarta menempati peringkat kedua secara nasional sebagai provinsi dengan indeks rawan bencana kebakaran permukiman tertinggi setelah provinsi Kalimantan selatan. (Kurniawan, Yunus, Amri, \& Pramudiarta, 2011).

$$
\text { Menurut Dinas }
$$

Pemadam Kebakaran DKI Jakarta dalam BPBD DKI Jakarta (2013), wilayah Jakarta Barat merupakan wilayah dengan kasus kebakaran gedung dan permukiman tertinggi mencapai 188 peristiwa. Daerah administratif Jakarta Barat yang rawan terhadap kebakaran salah satunya yaitu Kecamatan Tambora.

Kecamatan Tambora terdiri dari 11

Kelurahan merupakan salah satu kecamatan yang memiliki kondisi pemukiman padat di Jakarta Barat, sehingga rawan terhadap bahaya kebakaran. Peristiwa kebakaran yang terjadi pada Bulan April 2018 mengakibatkan 40 rumah warga hangus, dan 165 kepala keluarga dengan jumlah 660 jiwa terdampak kebakaran (Republika, 2018).

Pemetaan daerah bahaya dapat digunakan sebagai analisis perencanaan tata kota, perencanaan tanggap darurat terhadap bencana, penentuan asuransi, dan pembelajaran ekologi (Demir \& Kisi, 2016). Pemetaan atau zonasi kawasan bahaya merupakan salah satu bentuk mitigasi bencana secara non struktural, yang dapat menurunkan tingkat risiko suatu bencana. Persepsi masyarakat dapat digunakan untuk penilaian bahaya sebagai bentuk pendekatan social science, untuk mendeskripsikan daerah rawan berdasarkan informasi masyarakat lokal (Andrade \& Szlafsztein, 2015). Berdasarkan 
hal tersebut, artikel ini mendeskripsikan tingkat kerawanan Kebakaran menggunakan integrasi pendekatan penginderaan jauh dan persepsi masyarakat di Kecamatan Tambora Provinsi DKI Jakarta.

\section{METODE PENELITIAN}

Penelitian ini dilaksanakan pada Bulan Juli sampai Oktober tahun 2018, yang dilaksanakan di Kecamatan Tambora Jakarta Barat. Alat dan bahan yang digunakan dalam penelitian disajikan pada Tabel 1. Populasi dari penelitian adalah seluruh area permukiman Kecamatan Tambora Jakarta Barat. Metode penentuan sampel menggunakan area sampling, yaitu sampel diambil berdasarkan keterwakilannya pada setiap kelurahan.
Metode pengumpulan data dalam penelitian ini terdiri atas data primer dan data sekunder, dengan metode dokumentasi, observasi, dan wawancara. Data primer yang dikumpulkan dalam penelitian yaitu melalui survei lapangan untuk memperoleh informasi kondisi penggunaan lahan, kepadatan bangunan, material bangunan, jaringan listrik, lebar jalan, jarak dari sumber air, kondisi hidran, lokasi pos pemadam kebakaran, frekuensi kejadian, faktor-faktor penyebab kebakaran, waktu tanggap bencana, waktu kejadian. Data sekunder yang dikumpulkan dalam penelitian ini meliputi Peta RBI Skala 1:25000, Citra Quickbird, dan data yang diperoleh dari berbagai instansi seperti: BPS dan Pemadam Kebakaran Kecamatan Tambora.

Tabel 1. Bahan dan Alat Penelitian

\begin{tabular}{|c|c|c|}
\hline No & Bahan dan Alat & Fungsi \\
\hline 1 & GPS Garmin & Merekam titik koordinat \\
\hline 2 & $\begin{array}{c}\text { Perangkat Lunak Arc- } \\
\text { Gis } 10.3\end{array}$ & Analisis spasial \\
\hline 3 & $\begin{array}{c}\text { Kamera DigitalCanon } \\
\text { A2300 }\end{array}$ & Dokumentasi \\
\hline 4 & Kuesioner & $\begin{array}{l}\text { Mengumpulkan data } \\
\text { primer }\end{array}$ \\
\hline 5 & $\begin{array}{c}\text { Perangkat lunak } \\
\text { DNRGPS }\end{array}$ & $\begin{array}{c}\text { Transfer data hasil } \\
\text { tracking GPS }\end{array}$ \\
\hline 6 & Peta RBI skala 1:25.000 & Peta Administratif \\
\hline 7 & Citra QuickBird & Peta Penggunaan Lahan \\
\hline
\end{tabular}

Pembuatan peta kerawanan kebakaran menggunakan integrasi pendekatan natural dan social science, yaitu dengan integrasi pendekatan penginderaan jauh dan persepsi masyarakat. Pendekatan penginderaan jauh yaitu metode pengumpulan data dengan menggunakan interpretasi data citra Quickbird untuk identifikasi penggunaan lahan, kepadatan bangunan, lebar jalan, dan sungai. Pendekatan persepsi masyarakat digunakan untuk identifikasi frekuensi, historikal kejadian, dan upaya mitigasi kebakaran menggunakan metode wawancara mendalam.

Teknik pengolahan data yang digunakan yaitu data diolah menggunakan software Arc Gis 10.3, untuk menghasilkan peta- peta tematik yaitu peta Administratif, peta pra survei lapangan, peta distribusi hydran, peta kejadian kebakaran, peta penggunaan lahan dan peta zonasi kerawanan kebakaran. Peta kerawanan kebakaran diolah dan analisis dengan menggunakan teknik interpretasi, skoring, dan pembobotan. Angka pembobotan yang digunakan pada setiap parameter yaitu skala 0-20, bobot 20 merupakan bobot tertinggi sebagai pemberat untuk parameter yang dianggap penentu kerawanan. Skoring yang digunakan dengan skala 1-3, skala 1 menunjukkan nilai yang rendah terhadap kontribusi tingkat kerawanan kebakaran dan skala 3 merupakan nilai maksimum atau berpengaruh tinggi terhadap penentu tingkat kerawanan (Tabel 2). Penentuan kelas kerawanan yaitu dengan cara skor total maksmum di kurangi skor total minum dan dibagi jumlah kelas. Jumlah kelas kerawanan pada 
penelitian ini yaitu tiga kelas: rendah, sedang, dan tinggi.

Tabel 2. Pembobotan dan Skoring Parameter Kerawanan Kebakaran

\begin{tabular}{cccc} 
Parameter & Bobot & \multicolumn{2}{c}{ Skoring } \\
\cline { 3 - 4 } & & Minimum & Maksimum \\
\hline Frekuensi kejadian & 20 & 1 & 3 \\
\hline Penggunaan lahan & 10 & 1 & 3 \\
\hline Kepadatan bangunan & 10 & 1 & 3 \\
\hline Jumlah dan lokasi pemadam kebakaran & 15 & 1 & 3 \\
\hline Jenis dan lokasi sumber air & 10 & 1 & 3 \\
\hline Jumlah hydrant & 10 & 1 & 3 \\
\hline Material bangunan & 10 & 1 & 3 \\
\hline Jaringan listrik & 10 & 1 & 3 \\
\hline Waktu tanggap bencana & 5 & 1 & 3 \\
\hline
\end{tabular}

\section{HASIL DAN PEMBAHASAN \\ Deskripsi Wilayah Penelitian}

Kecamatan Tambora merupakan salah satu kecamatan di wilayah Kota Administrasi Jakarta Barat, terdiri atas 11 kelurahan yaitu Kalianyer, Duri Selatan, Tanah Sereal, Duri Utara, Krendang, Jembatan Besi, Angke, Jembatan Lima,
Tambora, Roa Malaka, dan Pekojan. Secara geografis terletak di $106^{\circ} 22^{\prime} 42^{\prime \prime}$ BT - $106^{\circ}$

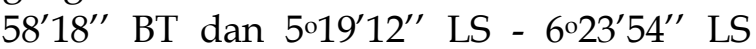
(Gambar 1). Jumlah RW (Rukun Warga) yaitu 96 dan jumlah RT ( Rukun Tetangga) yaitu 1.082. Luas wilayah yaitu $5,40 \mathrm{~km}^{2}$.

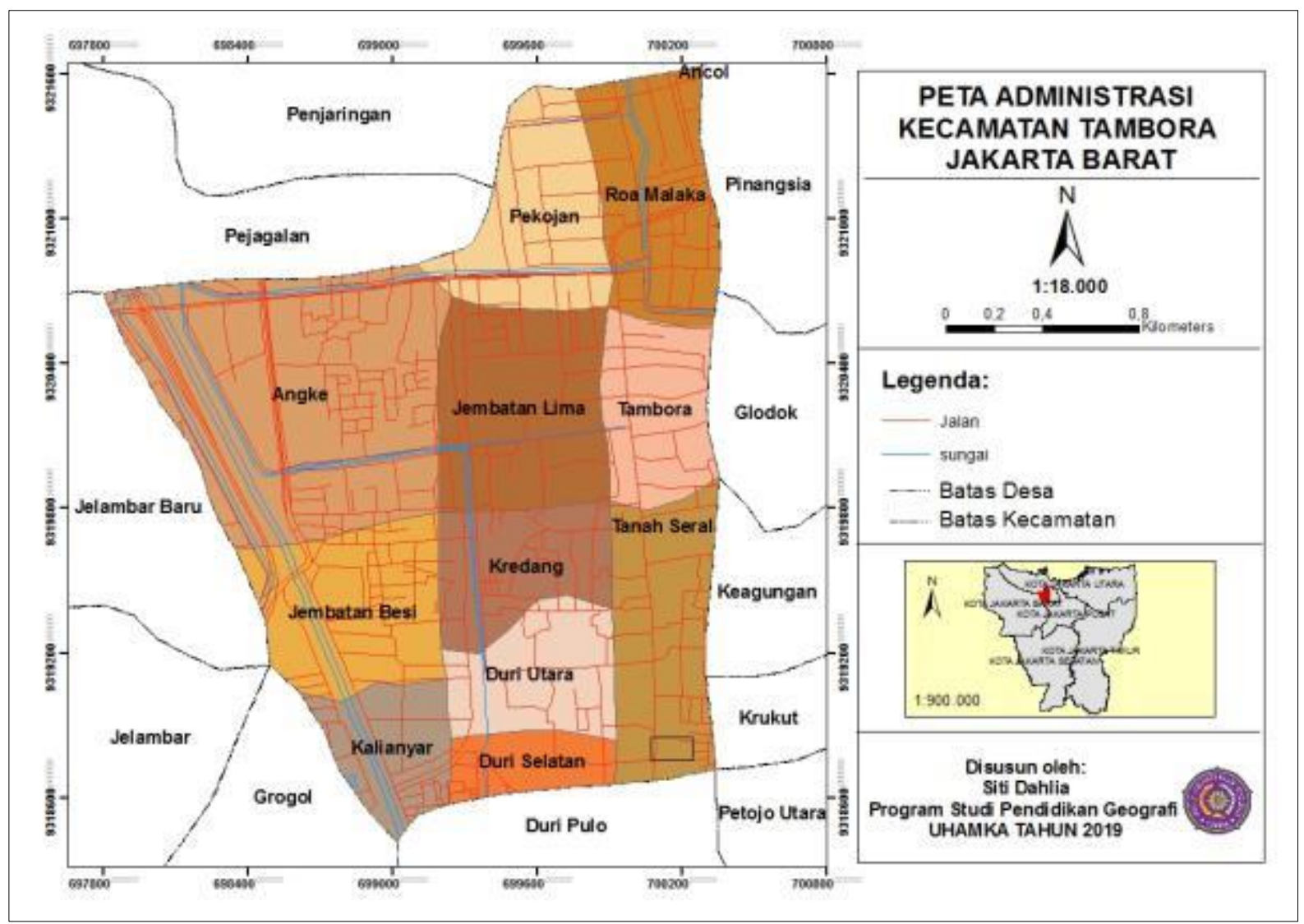

Gambar 1. Peta Lokasi Penelitian

Analisis Kerawanan Kebakaran di Kecamatan Tambora Provinsi DKI Jakarta

Peta kerawanan merupakan peta yang menyajikan informasi suatu kejadian secara spasial, yang bertujuan untuk sebagai bahan pertimbangan perencanaan dan upaya mitigasi untuk pihak pengambil kebijakan dalam rangka mengurangi risiko. 
Pada penelitian ini pembuatan peta kerawanan menggunakan 9 parameter yaitu: frekuensi kejadian, penggunaan lahan, kepadatan bangunan, jumlah dan lokasi pemadam kebakaran, jenis dan lokasi sumber air, jumlah hydrant, material bangunan, jaringan listrik, dan waktu tanggap bencana.

\section{Frekuensi Kejadian}

Frekuensi kejadian kebakaran di Wilayah Kecamatan Tambora sampai tahun 2017 di sajikan pada Tabel 3.

Tabel 3. Frekuensi Kejadian Kebakaran

\begin{tabular}{cc} 
Nama Kelurahan & Frekuensi Kejadian \\
Kalianyar & 0 \\
\hline Duri Selatan & 3 \\
\hline Tanah Sereal & 1 \\
\hline Duri Utara & 4 \\
\hline Krendang & 2 \\
\hline Jembatan Besi & 6 \\
\hline Angke & 6 \\
\hline Jembatan Lima & 2 \\
\hline Tambora & 0 \\
\hline Roa Malaka & 3 \\
\hline Pekojan & 1
\end{tabular}

Sumber: Kecamatan Tambora dalam Angka Tahun 2017

Kelurahan dengan frekuensi kejadian terbanyak yaitu Kelurahan Jembatan Besi dan Angke sebanyak 6 kali, dan Kelurahan Duri Utara sebanyak 4 kali. Frekuensi kejadian terendah yaitu Kelurahan Kalianyer dan Tambora dengan tidak pernah terjadi. Frekuensi kejadian kebakaran suatu wilayah menunjukkan kemungkinan bahaya kebakaran dapat terulang di wilayah tersebut, semakin tinggi frekuensi kejadian kebakaran suatu wilayah maka semakin tinggi kemungkinan wilayah tersebut mengalami kebakaran kembali Perka BNPB No. 2 (2012). Gambar lokasi terbakar di sajikan pada Gambar 2, dan peta distribusi daerah kejadian kebakaran di Kecamatan Tambora disajkian pada Gambar 3.

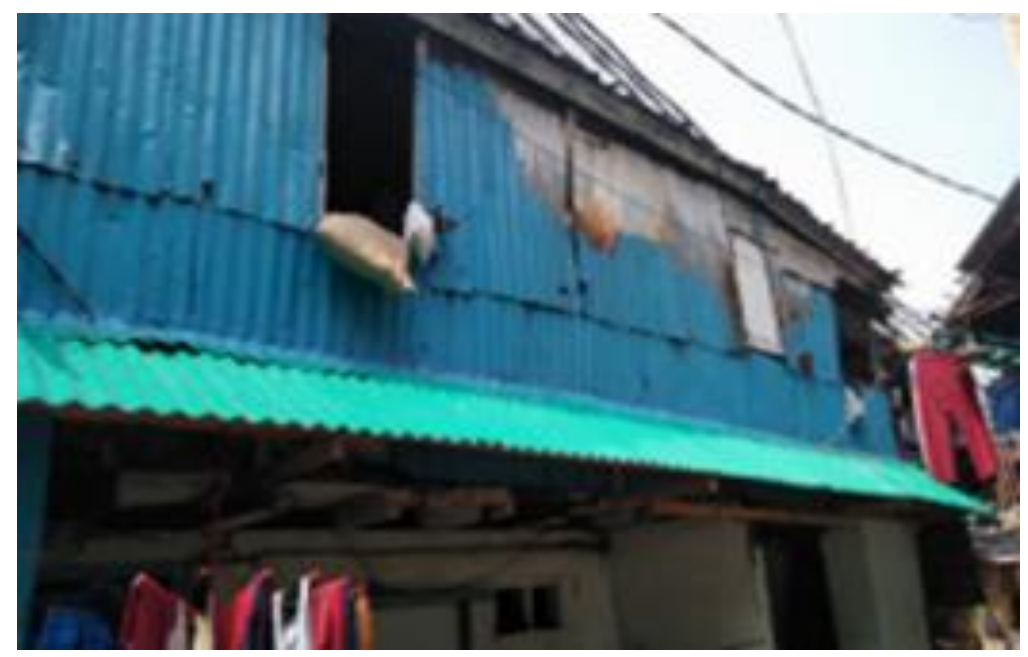

Gambar 2. Gambar lokasi area terbakar di Kelurahan Angke 


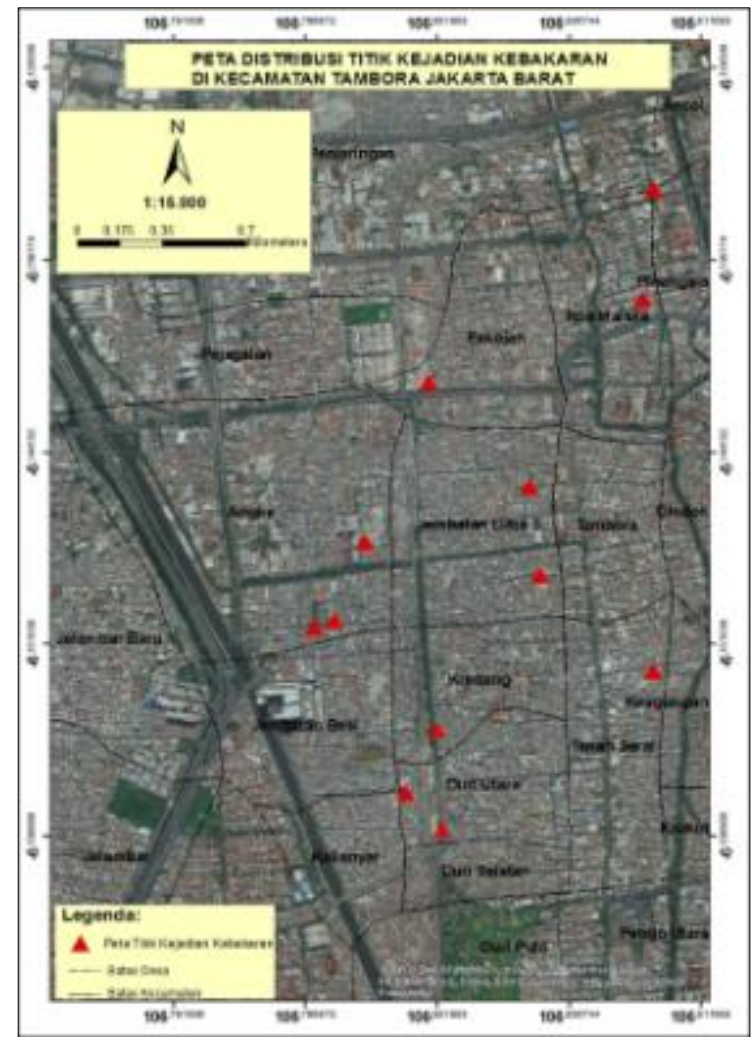

Gambar 3. Peta titik daerah kejadian kebakaran di Kecamatan Tambora

\section{Penggunaan Lahan}

Mayoritas penggunaan lahan wilayah penelitian yaitu pemukiman, rincian data penggunaan lahan setiap kelurahan di sajikan pada Tabel 4. Kondisi masyoritas penggunaan lahan wilayah penelitian yang merupakan pemukiman mengakibatkan wilayah penelitian rawan terjadi kebakaran di area pemukiman, karena aktifitas peralatan masak seperti kompor gas dan home industri berupa sablon dan jahit. Selain itu, penggunaan lahan lainnya terdapat pasar dan ruko, yang di beberapa kelurahan merupakan area sering terbakar karena faktor konsleting listrik.

Tabel 4. Penggunaan Lahan Wilayah Penelitian

\begin{tabular}{ccc}
\hline No & Nama Kelurahan & Kepadatan \\
\hline 1 & Kalianyar & Sangat Padat \\
\hline 2 & Duri Selatan & Sangat Padat \\
\hline 3 & Tanah Sereal & Sangat Padat \\
\hline 4 & Duri Utara & Padat \\
\hline 5 & Krendang & Sangat Padat \\
\hline 6 & Jembatan Besi & Sangat Padat \\
\hline 7 & Angke & Sangat Padat \\
\hline 8 & Jembatan Lima & Sangat Padat \\
\hline 10 & Tambora & Sangat Padat \\
\hline 11 & Roa Malaka & Padat \\
\hline
\end{tabular}

Sumber: Hasil Penelitian, 2018 


\section{Kepadatan Bangunan}

Kondisi kepadatan bangunan wilayah penelitian mayoritas sangat padat sampai padat, karena mayoritas jarak antar rumah merupakan 0,5 - 1 meter. Kategori pemukiman tidak padat yaitu jika jarak antar rumah lebar yaitu lebih dari 3 meter, kategori jarak sedang yaitu antara 1,5 meter sampai 3 meter, sedangkan kategori jarak rapat yaitu kurang dari 1,5 meter, sangat rapat yaitu menempel atau tidak ada jarak (Adilla, Adyatma, \& Arisanty, 2016). Deskripsi tingkat kepadatan pada setiap kelurahan di sajikan pada Tabel 5. Kondisi wilayah penelitian dengan tingkat kepadatan bangunan yang sangat padat sampai padat, merupakan salah satu faktor pemicu tingginya wilayah penelitian rawan terhadap kebakaran. Hal ini di sebabkan karena kualitas lingkungan, aktivitas penduduk, dan akses upaya evakuasi yang sulit. Kondisi di lapangan terkait salah satu contoh gambar kondisi kepadatan pemukiman disajikan pada Gambar 4 .

Tabel 5. Kepadatan Bangunan

\begin{tabular}{ccc}
\hline No & Nama Kelurahan & Penggunaan Lahan \\
\hline 1 & Kalianyar & Pemukiman \\
\hline 2 & Duri Selatan & Pemukiman, Pasar \\
\hline 3 & Tanah Sereal & Pemukiman, Ruko \\
\hline 4 & Duri Utara & Pemukiman \\
\hline 5 & Krendang & Pemukiman, Ruko \\
\hline 6 & Jembatan Besi & Pemukiman, pasar, ruko \\
\hline 7 & Angke & Pemukiman, Stasiun \\
\hline 8 & Jembatan Lima & Pemukiman dan ruko \\
\hline 9 & Tambora & Pemukiman, Sekolah, dan lahan kosong \\
\hline 10 & Roa Malaka & Pemukiman kelas menengah, Ruko, Masjid, dan Bank \\
\hline 11 & Pekojan & Pemukiman \\
\hline
\end{tabular}

Sumber: Hasil Penelitian, 2018

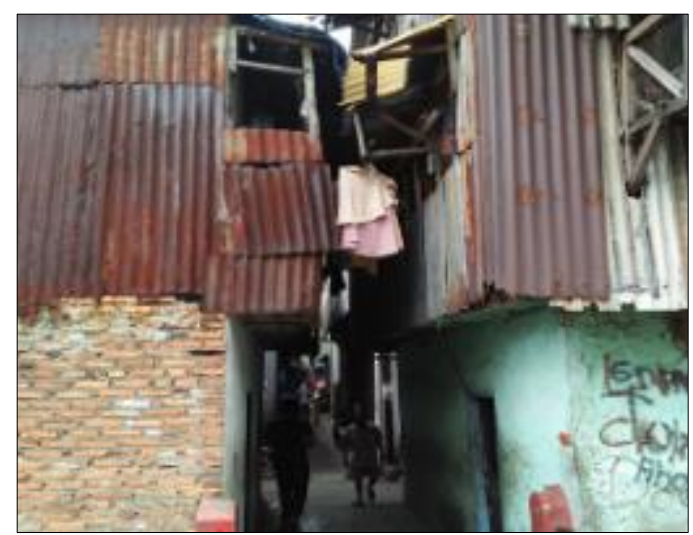

Gambar 4. Kondisi pemukiman di Kelurahan Duri Selatan

4. Jumlah dan Lokasi Pemadam

Kebakaran

Pada wilayah rawan terjadi kebakaran jumlah dan jarak lokasi damkar merupakan faktor penting sebagai tindakan tangap darurat dari bencana kebakaran. Hasil temuan di lapangan menunjukkan bahwa tidak semua kelurahan di Kecamatan Tambora memiliki damkar, data kelurahan yang memiliki damkar di sajikan pada Tabel 6. Wilayah yang memiliki damkar yaitu Kelurahan Krendeng, Jembatan Besi, Angke, Roa Malaka dan Jembatan Lima. Menurut informasi hasil survei lapangan pada Kelurahan Angke kantor damkar 
dibangun setelah kejadian kebakaran besar tahun 2011. Pada Kelurahan Roa Malaka merupakan kantor pemadam kebakaran sektor Kecamatan Tambora. Pada Kelurahan Kalianyar, Duri Selatan, Tanah Sereal, Duri Utara merupakan kelurahan tidak tersedia damkar karena jika terjadi kebakaran menggunakan damkar dari Kelurahan Krendeng. Kondisi tersebut mengakibatkan menambah potensi tingkat kerawanan kebakaran pada kelurahan tersebut, karena jarak lokasi damkar yang berbeda kelurahan sehingga membutuhkan waktu untuk mencapai lokasi.

Tabel 6. Ketersediaan Kantor Pemadam Kebakaran

\begin{tabular}{ccc} 
No & Nama Kelurahan & Keterangan \\
\hline $\mathbf{1}$ & Kalianyar & tidak ada \\
\hline $\mathbf{2}$ & Duri Selatan & tidak ada \\
\hline $\mathbf{3}$ & Tanah Sereal & tidak ada \\
\hline $\mathbf{4}$ & Duri Utara & tidak ada \\
\hline $\mathbf{5}$ & Krendang & ada \\
\hline $\mathbf{6}$ & Jembatan Besi & ada \\
\hline $\mathbf{7}$ & Angke & ada \\
\hline $\mathbf{8}$ & Jembatan Lima & ada \\
\hline $\mathbf{9}$ & Tambora & tidak ada \\
\hline $\mathbf{1 0}$ & Roa Malaka & ada \\
\hline $\mathbf{1 1}$ & Pekojan & tidak ada \\
\hline
\end{tabular}

Sumber: Hasil Penelitian, 2018

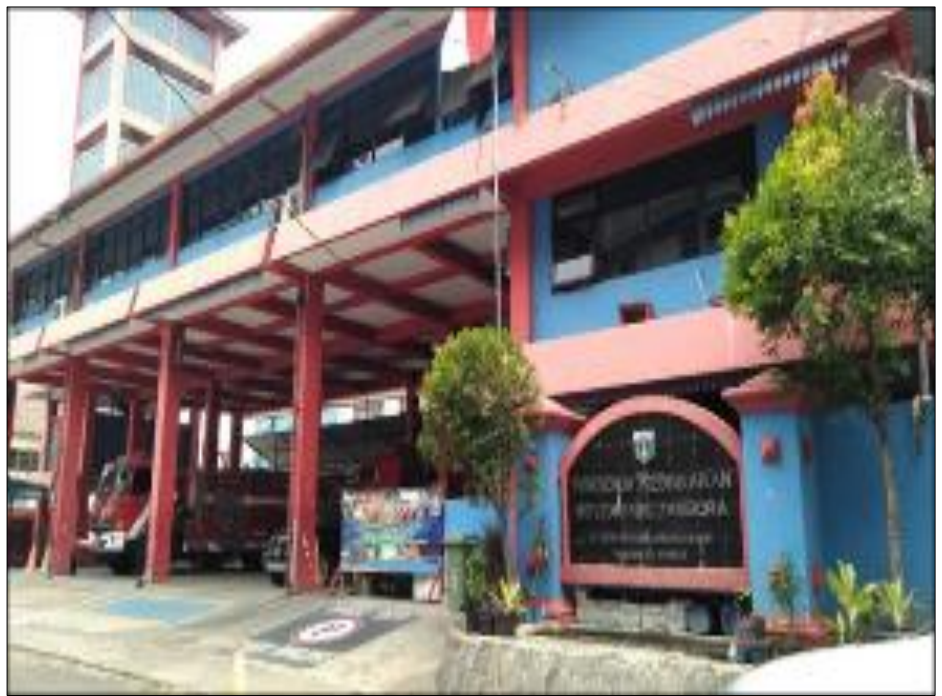

Gambar 5. Lokasi kantor pemadam kebakaran sektor Kecamatan Tambora

5. Jenis dan lokasi sumber air

Sumber air merupakan penting pada area rawan terbakar, hal ini sebagai salah satu material yang dapat digunakan ketika kondisi darurat kebakaran. Wilayah Kecamatan Tambora di lalui oleh beberapa sungai yaitu Kali Krukut, Kali Besar, Kali Duri, Kali Cibubur, Kali Tubagus Angke, Kali Jembatan Dua, Kali Duri Ledeng, dan Keli Jelakeng. Kondisi ini memiliki peran positif yang dimanfaatkan oleh masyarakat setempat untuk memadamkan api ketika kondisi darurat kebakaran. Selain sungai, sumber air untuk memadamkan kebakaran juga berasal dari air masjid, air selokan, penampung air, dan tabung pemadam kebakaran (Tabel 7). Kondisi salah satu sungai di Kelurahan Kepajon yang dapat dimanfaatkan untuk pemdaman kebakaran pada kondisi darurat disajikan pada Gambar 6. 
Tabel 7. Sumber Air Pemadam Kebakaran Kecamatan Tambora

\begin{tabular}{ccc} 
No & Nama Kelurahan & Sumber Air \\
$\mathbf{1}$ & Kalianyar & air selokan, air masjid, dan penampung air \\
\hline $\mathbf{2}$ & Duri Selatan & sungai \\
\hline $\mathbf{3}$ & Tanah Sereal & sungai dan tabung pemadam \\
\hline $\mathbf{4}$ & Duri Utara & sungai \\
\hline $\mathbf{5}$ & Krendang & sungai \\
\hline $\mathbf{6}$ & Jembatan Besi & sungai \\
\hline $\mathbf{7}$ & Angke & sungai \\
\hline $\mathbf{8}$ & Jembatan Lima & sungai \\
\hline $\mathbf{9}$ & Tambora & sungai \\
\hline $\mathbf{1 0}$ & Roa Malaka & sungai \\
\hline $\mathbf{1 1}$ & Pekojan & sungai \\
\hline
\end{tabular}

Sumber: Hasil Penelitian, 2018

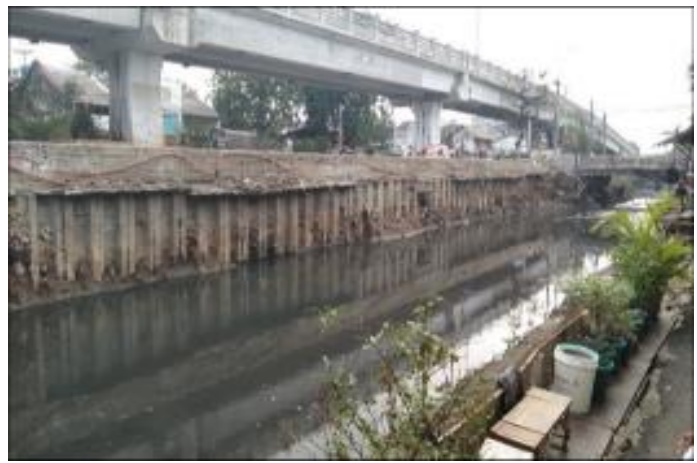

Gambar 6. Sungai di Kelurahan Kepajon

\section{Jumlah Hydrant}

Hydrant adalah sistem salah satu pemadam kebakaran yang terhubung dengan sumber air yang bertekanan dan mendistribusikan air ke lokasi pemadaman dengan laju yang cukup. Pada wilayah Kecamatan Tambora tidak semua kelurahan memiliki hydrant, kelurahan yang memiliki jumlah hydrant terbanyak yaitu Kelurahan Tambora, sedangkan kelurahan yang tidak memiliki hydrant yaitu Kelurahan Duri Utara, Roa Malaka dan Pekajon. Kondisi kelurahan yang tidak memiliki hydrant disebabkan karena kelurahan tersebut dekat dengan lokasi pemadam kebakaran, sehigga tidak di sediakan hydrant. Rincian ketersedian hydrant pada setiap kelurahan disajikan pada Tabel 8, peta citra distribusi hydrant di Kecamatan Tambora disajikan pada Gambar 7.

Tabel 8. Jumlah Hydrant di setiap Kelurahan Kec. Tambora

\begin{tabular}{ccc} 
No & Nama Kelurahan & Jumlah \\
\hline 1 & Kalianyar & 1 \\
\hline 2 & Duri Selatan & 2 \\
\hline 3 & Tanah Sereal & 1 \\
\hline 4 & Duri Utara & 0 \\
\hline 5 & Krendang & 1 \\
\hline 6 & Jembatan Besi & 0 \\
\hline 7 & Angke & 2 \\
\hline 8 & Jembatan Lima & 1 \\
\hline 9 & Tambora & 8 \\
\hline 10 & Roa Malaka & 0 \\
\hline 11 & Pekojan & 0 \\
\hline
\end{tabular}

Sumber: Hasil Penelitian, 2018 


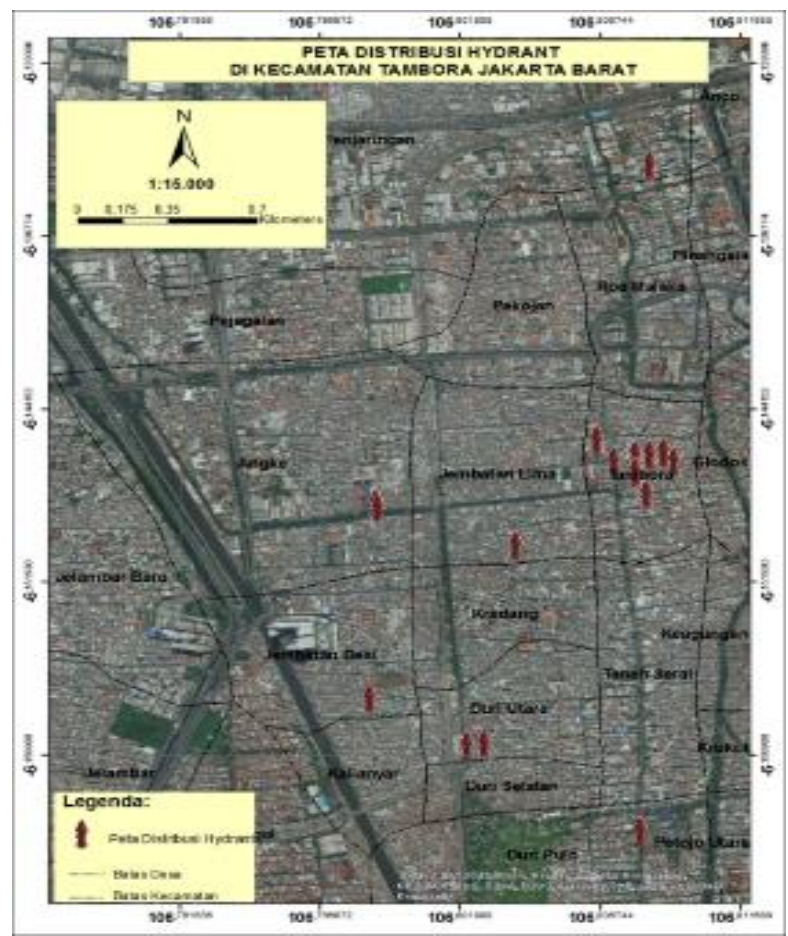

Gambar 7. Distribusi Hydrant di Kelurahan Tambora

7. Material Bangunan

Material bangunan merupakan salah satu komponen untuk mengetahui seberapa besar bangunan tersebut rentan terhadap kebakaran. Jenis karakteristik material bangunan rumah penduduk dibagi kedalam dua golongan yaitu jenis rumah permanen yaitu rumah yang memiliki material yang tahan api (jenis rumah tembok) dan rumah semi permanen yaitu rumah yang banyak menggunakan material kayu, dan bangunan untuk jenis rumah semi permanent merupakan rumah yang rentan terhadap kebakaran (Nurwulandari, 2016). Jenis bangunan di Kecamatan Tambora mayoritas merupakan bangunan semi permanen yaitu kombinasi tembok, kayu, asbes, dan seng. Kelurahan yang memiliki mayoritas bangunan permanen yaitu Kelurahan Roa Malaka (Tabel 9).

Tabel 9. Material bangunan di Kecamatan Tambora

\begin{tabular}{cll} 
No & Nama Kelurahan & Keterangan \\
1 & Kalianyar & Batu, Seng, Genting \\
\hline 2 & Duri Selatan & Batu, genting, kayu \\
\hline 3 & Tanah Sereal & semen, beton, seng \\
\hline 4 & Duri Utara & Batu, genting \\
\hline 5 & Krendang & beton, semen, asbes, seng \\
\hline 6 & Jembatan Besi & semen, asbes, beton \\
\hline 7 & Angke & Batu, kayu, asbes, dan seng \\
\hline 8 & Jembatan Lima & semen, asbes, beton, seng \\
\hline 9 & Tambora & Batu, kayu, asbes, dan seng \\
\hline 10 & Roa Malaka & Batu, genting (permanent) \\
\hline 11 & Pekojan & Batu, kayu, asbes, dan seng (Sebagian Permanent) \\
\hline
\end{tabular}

Sumber: Hasil Penelitian, 2018 


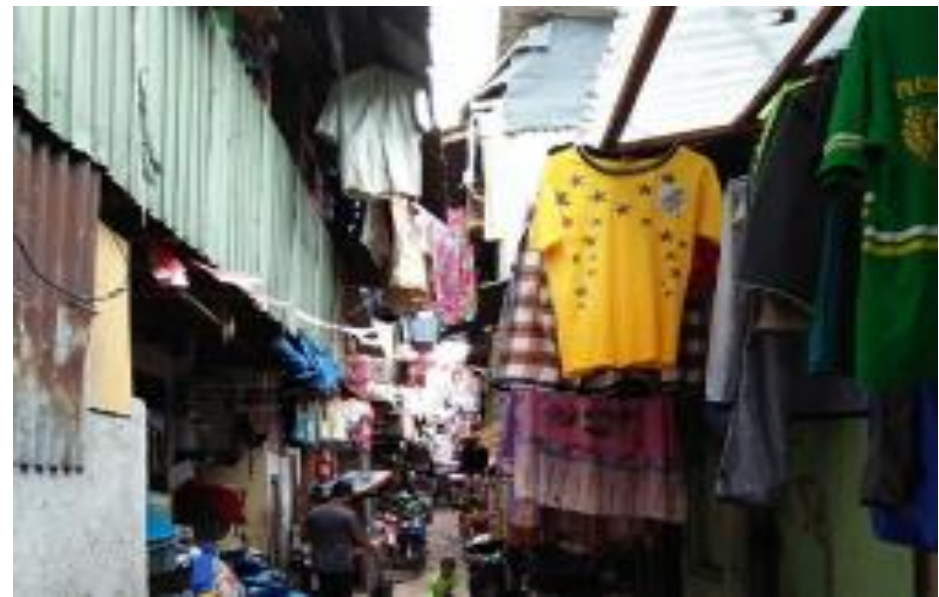

Gambar 8. Contoh Karakteristik Material Banguan Pemukiman di Kec. Tambora

8. Jaringan Listrik

Kebakaran yang sering terjadi di pemukiman pada umumnya disebabkan oleh instalasi listrik, karena pemasangan instalasi yang tidak sempurna, penggunaan alat atau instalasi yang tidak standar atau kurang aman, penggunaan listrik dengan cara tidak aman, serta penggunaan peralatan yang tidak baik atau rusak (Adilla et al., 2016). Mayoritas wilayah Kecamatan Tambora memiliki instalasi atau jaringan listrik tidak baik, yaitu hampir di setiap kelurahan kondisi jaringan listrik tidak teratur yaitu kabel listrik saling bertumpukan, ketinggian kabel listrik rendah, dan terdapat warga yang memanfaatkannya untuk gantungan jemuran. Kondisi tersebut yang mengakibatkan wilayah penelitian rawan terhadap kebakaran, karena faktor konsleting listrik. Rician kondisi jaringan listrik setiap kelurahan di sajikan pada Tabel 10, dan salah satu contoh kondisi jaringan listrik disajikan pada Gambar 9.

Tabel 10. Kondisi Jaringan Listrik setiap Kelurahan di Kec. Tambora

\begin{tabular}{ccc} 
No & Nama Kelurahan & Jaringan Listrik \\
\hline 1 & Kalianyar & tidak baik \\
\hline 2 & Duri Selatan & tidak baik \\
\hline 3 & Tanah Sereal & tidak baik \\
\hline 4 & Duri Utara & tidak baik \\
\hline 5 & Krendang & tidak baik \\
\hline 6 & Jembatan Besi & Baik \\
\hline 7 & Angke & tidak baik \\
\hline 8 & Jembatan Lima & tidak baik \\
\hline 9 & Tambora & tidak baik \\
\hline 10 & Roa Malaka & sebagian tidak baik \\
\hline 11 & Pekojan & tidak baik
\end{tabular}

Sumber: Hasil Penelitian, 2018 


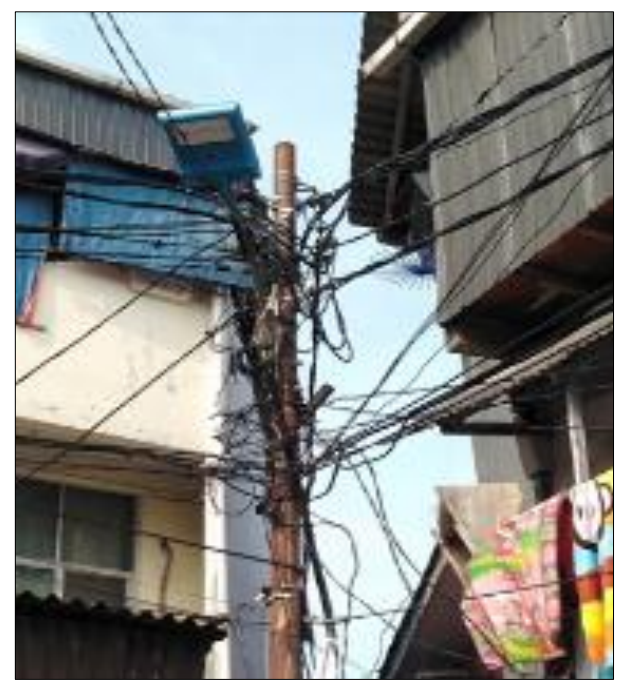

Gambar 9. Kondisi jaringan listrik

9. Waktu Tanggap Bencana

Waktu tanggap bencana yaitu kecapatan waktu yang dibutukan oleh tim pemadam kebakaran, untuk sampai ke lokasi kejadian kebakaran. Hasil wawancara dengan penduduk sekitar menunjukkan bahwa kelurahan dengan waktu tercepat tim pemadam kebakaran datang ke lokasi yaitu Kelurahan Tanah Sereal, Angke, Tambora, Roa Malaka yaitu \pm 0-20 menit. Kelurahan Duri Utara, Krendang, Jembatan Besi, dan Jembatan Lima membutuhkan waktu \pm 30 menit. Kelurahan Kalianyar, Duri Selatan, dan Pekajon membutuhkan waktu 1-2 jam.
Kondisi kecepatan dan kelembatan datangnya tim pemadam kebakaran karena faktor kondisi jarak lokasi kantor damkar dan akses jalan. Kelurahan yang kedatangan tim pemdam kebakaran lebih cepat karena kelurahan tersebut memiliki kantor damkar atau berada di kelurahan terdekat dan akses jalan mudah. Kelurahan yang kedatangan tim damkar lebih lambat karena faktor kelurahan tersebut tidak memiliki kantor damkar dan akses jalan yang sulit atau sempit (Gambar 10).

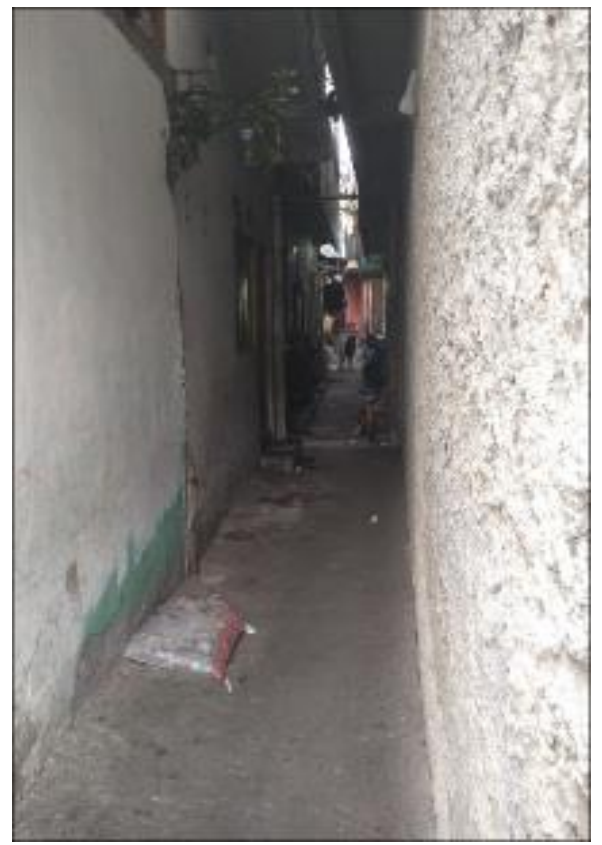

Gambar 10. Kondisi Jalan Gang Kelurahan Pekajon 
Berdasarkan parameter-parameter yang di deskripsikan diatas selanjutnya dilakukan analisis menggunakan metode pembobotan dan skoring (Tabel 2), sehingga menghasilkan peta kerawanan kebakaran dengan kelasifikasi tiga kelas yaitu rendah dengan warna hijau, sedang warna kuning, dan tinggi warna merah (Gambar 11). Hasil analisis menunjukkan bahwa Kecamatan Tambora dengan tingkat kerawanan Tinggi seluas $258 \mathrm{Ha}$, tingkat kerawanan sedang seluas $113 \mathrm{Ha}$, dan tingkat kerawanan rendah seluas $137 \mathrm{Ha}$. Kondisi tersebut menunjukkan bahwa mayoritas Kecamatan Tambora memiliki tingkat kerawanan kebakaran tinggi. Kondisi tersebut di pengaruhi oleh faktor: frekuensi kejadian yang sering berulang, penggunaan lahan yang merupakan mayoritas pemukiman dengan kepadatan tinggi, material bangunan yang mayoritas bangunan semi permanen yaitu berbahan tembok kombinasi kayu, seng, dan asbes, dan jaringan listrik yang tidak aman atau memenuhi standar.

Kelurahan dengan tingkat
kerawanan kebakaran tinggi yaitu Kelurahan Pekajon, Angke, Krendeng, Duri Utara, dan Kalianyer. Kelurahan dengan tingkat kerawanan kebakaran sedang yaitu Tanah Sereal, Jembatan Besi, dan Duri Selatan. Kelurahan dengan tingkat kerawanan kebakaran rendah yaitu Roa Malaka, Jembatan Lima, dan Tambora. Mayoritas kelurahan di Kecamatan Tambora berada pada zonasi daerah kerawanan tinggi terhadap kebakaran.

Kelurahan Pekajon, Angke, Krendeng, Duri Utara, dan Kalianyer merupakan kelurahan dengan tingkat kerawanan tinggi karena faktor berdasarkan frekuensi kejadian sudah mengalami 1-6 kali kejadian, kepadatan bangunan merupakan bangunan dengan kondisi sangat padat, kator damkar yang tersedia hanya di Kelurahan Angke dan Kerendang, sumber air hanya berasal dari sungai, material bangunan mayoritas bangunan semi permanen, kondisi jaringan listrik tidak baik atau tidak standar, jumlah hidrant hanya 0-2, dan waktu kedatangan tim pemadam kebakaran sampai 2 jam.
Kelurahan Tanah Sereal, Jembatan Besi, dan Duri Selatan merupakan daerah yang memiliki tingkat kerawanan sedang karena frekuensi kejadian 1-6 kali, mayoritas penggunaan lahan merupakan pemukiman dengan kepadatan bangunan merupakan sangat padat, pos damkar terdapat di Kelurahan Jembatasn Besi, sumber air berasal dari sungai dan tabung pemadam, material bangunan terdapat bangunan semi permanen dan berbenton, jaringan listrik pada Kelurahan Jembatan Besi kondisi baik atau aman dan Kelurahan Tanah Sereal dan Duri Selatan tidak baik, jumlah hydrant yang tersedia 1-2 setiap kelurahan, dan waktu tanggap membutuhkan 20 menit sampai satu jam.

Kelurahan Roa Malaka, Jembatan Lima, dan Tambora merupakan kelurahan dengan tingkat kerawanan rendah karena faktor frekuensi kejadian 0-3 kali, mayoritas penggunaan lahan dengan kondisi padat sampai sangat padat, kantor damkar hanya ada pada jembatan lima, sumber air berupa sungai, material bangunan semi permanent sampai permanen, jaringan listrik tidak baik sampai baik, jumlah hydrant 0-8, dan waktu tanggap yaitu 0-30 menit.

Wilayah Kecamatan Tambora memiliki kerawanan tinggi terhadap kebakaran, faktor penyebab terjadinya kebakaran di wilayah penelitian beragam. Faktor alam yang menyebabkan kebakaran diantaranya adalah petir, gempa bumi, letusan gunung api, kekeringan dan lain-lain, sedangkan kebakaran yang disebabkan oleh faktor manusia adalah berasal dari kebocoran gas, hubungan arus pendek listrik, puntung rokok, sabotase, rendahnya sistem pengaman konstruksi bangunan terhadap kebakaran, dan lain-lain Undang-Undang RI No. 24 (2007). Menurut data BPS faktor penyebab kebakaran Kecamatan Tambora mayoritas merupakan konsleting listrik sebanyak 30 kejadian, kondisi tersebut karena instalasi jaringan listrik wilayah penelitian tidak baik atau tidak standar. Faktor penyebab lainnya yaitu 3 kejadian merupakan ledakan kompor gas, karena kondisi wilayah penelitian yang merupakan mayoritas pemukiman sangat padat, sehingga tingginya kecepatan jalur 
perambatan api ke pemukiman lainnya.

lainnya seperti: kebakaran karena lilin ketika Selanjutnya, 5 kejadian merupakan faktor mati lampu (Gambar 12).

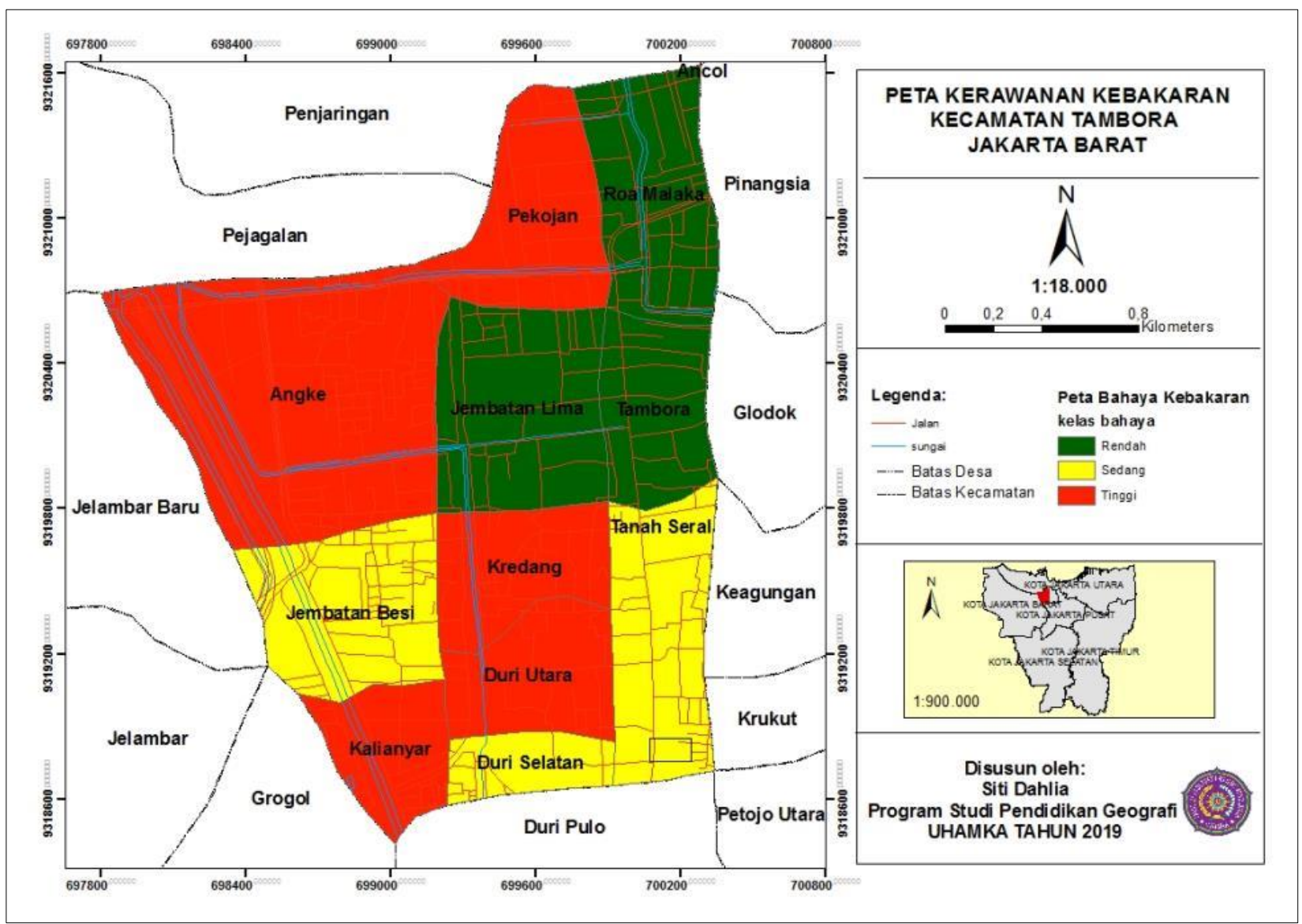

Gambar 11. Peta Kerawanan Kebakaran Kecamatan Tambora

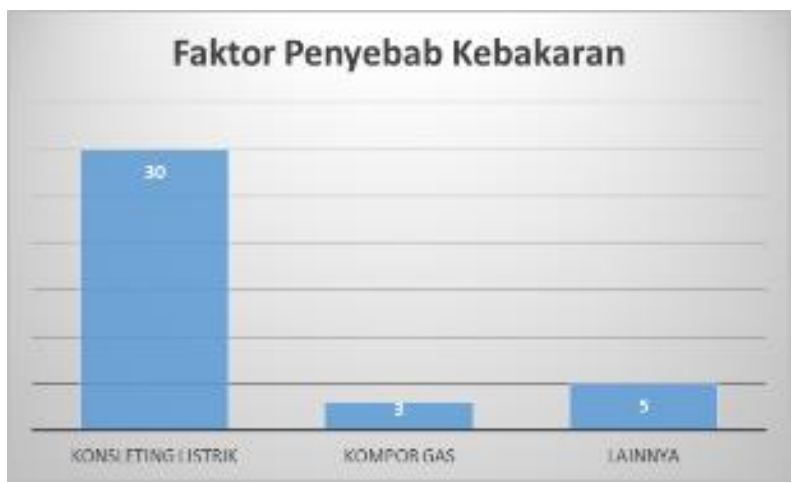

Gambar 12. Faktor-Faktor Pentebab Kebakaran di Kecamatan Tambora

\section{Upaya Mitigasi Bencana Kebakaran}

Mitigasi adalah hal - hal yang dilakukan untuk mengurangi risiko bencana baik secara struktural (pembangunan fisik bangunan) maupun non struktural (pendidikan dan pelatihan terkait bencana dan kebijakaan penggunaan lahan (Marfa'i, 2012). Pencegahan kebakaran pada bangunan gedung adalah mencegah terjadinya kebakaran pada bangunan gedung atau ruang kerja. Bila kondisi-kondisi yang berpotensi terjadinya kebakaran dapat dikenali dan dieliminasi akan dapat mengurangi secara substansial terjadinya kebakaran Peraturan Menteri Pekerjaan Umum No. 26 (2008). Kecamatan Tambora merupakan wilayah yang rawan terhadap terjadinya kebakaran, untuk itu penting upaya mitigasi baik secara 
struktural dan non struktural untuk mengurangi tingkat risiko.

Upaya-upaya mitigasi sudah dilakukan oleh pemerintah atau masyarakat untuk pengurangan tingkat risiko kebakaran, baik secara struktural ataupun non struktural. Upaya mitigasi kebakaran secara struktural yaitu: sudah ada alarm kebakaran yang di pasang di Kelurahan Duri Selatan, perbaikan hydrant yang rusak dan penambahan jumlah hydrant, pengadaan tabung kebakaran di setiap balai, dan penambahan pendirian pos pemadam kebakaran. Upaya mitigasi secara non struktural yaitu ada pelatihan mitigasi kebakaran yang dilakukan oleh BPBD DKI Jakarta bersama pihak kelurahan untuk karang taruna setiap kelurahan.

\section{KESIMPULAN}

Hasil analisis menunjukkan bahwa wilayah Kecamatan Tambora mayoritas merupakan area kerawanan tingkat tinggi seluas $258 \mathrm{Ha}$, tingkat kerawanan sedang seluas $113 \mathrm{Ha}$, dan tingkat kerawanan rendah seluas $137 \mathrm{Ha}$. Kelurahan dengan tingkat kerawanan kebakaran tinggi yaitu Kelurahan Pekajon, Angke, Krendeng, Duri Utara, dan Kalianyer. Kelurahan dengan tingkat kerawanan kebakaran sedang yaitu Tanah Sereal, Jembatan Besi, dan Duri Selatan. Kelurahan dengan tingkat kerawanan kebakaran rendah yaitu Roa Malaka, Jembatan Lima, dan Tambora. Faktor - faktor yang mempengaruhi tingkat kerawanan yaitu: frekuensi kejadian yang sering berulang, penggunaan lahan yang merupakan mayoritas pemukiman dengan kepadatan tinggi, material bangunan yang mayoritas bangunan semi permanen yaitu berbahan tembok kombinasi kayu, seng, dan asbes, jaringan listrik yang tidak aman atau tidak memenuhi standar, jumlah hydrant, dan akses jalan yang sempit.

\section{UCAPAN TERIMA KASIH}

Pada kesempatan ini penulis menyampaikan ucapan terimakasih kepada Lemlitbang UHAMKA sebagai pendana kegiatan penelitian, FKIP UHAMKA dan Tim peneliti dosen pendidikan geografi UHAMKA, serta mahasiswa yang telah mendukung dan mengsukseskan terselesaikannya penelitian terkait pemetaan daerah kerawanan kebakaran Kecamatan Tambora Jakarta Barat. Semoga hasil penelitian ini dapat bermanfaat.

\section{DAFTAR PUSTAKA}

Adilla, Y., Adyatma, S., \& Arisanty. (2016). Faktor Penyebab Kerentanan Kebakaran Berdasarkan Persepsi Masyarakat di Kelurahan Melayu Kecamatan Banjarmasin Tengah, Jurnal Pendidikan Geografi, 3 (4), 40-57.

Andrade \& Szlafsztein. (2015). Community Participation in Flood Mapping in the Amazon Through Interdisciplinary Methods, Journal of Natural Hazards, 78, 1491-1500.

Badan Penanggulangan Bencana Daerah Provinsi DKI Jakarta (2013). Rencana Penanggulangan Bencana Provinsi DKI Jakarta Tahun 2013-2017.

Demir, Vahdettin., \& Kisi, Ozgur. (2016). Flood Hazard Mapping by Using Geographic Information System and Hydraulic Model: Mert River, Samsun, Turkey, Advances in Meteorology, http:/ / dx.doi.org/10.1155/2016/4891 015.

https://www.republika.co.id/berita/nasio nal/jabodetabeknasional/18/04/23/p7mwyt330sandi-korban-kebakaran-tamboraditangani-dengan-baik.

Januandari, M.A., Rachmawati T.A., \& Sufianto H. (2017). Analisa Risiko Bencana Kebakaran Kawasan Segiempat Tunjungan Surabaya, Jurnal Pengembangan Kota, 5 (2), 149-158. DOI: 10.14710/jpk.5.2.149-158.

Kurniawan, L., Yunus, R., Amri, M. R., \& Pramudiarta, N. (2011). Indeks Rawan Bencana Indonesia. Jakarta: BNPB.

Marfa'i, MA,, (2012). Modul Kuliah Pengelolaan Kebencanaan di Indonesia, Yogyakarta: Fakultas Geografi Universitas Gadjah Mada. 
Nurwulandari, F.S., (2016). Kajian Mitigasi Bencana Kebakaran di Permukiman Padat (Studi Kasus: Kelurahan Taman Sari, Kota Bandung, Jurnal Infomatek Volume 18 (1), 27-36.

Paripurno, E. T., Junaedi, E., Susanto, D., Dwirahmadi, F., Haryanto, A. A., Amin, S., Waskito, N. B., \& Sofyan., Nisrina, I. (2012). Rencana Penanggulangan Bencana. Jakarta: BPBD DKI Jakarta.

Peraturan Kepala BNPB. (2012). Pedoman Umum Pengkajian Risiko Bencana Nomor: 02 Tahun 2012. BNPB. Jakarta.

Peraturan Menteri Pekerja Umum. (2008). Persyaratan Teknis Sistem Proteksi Kebakaran pada Bangunan Gedung dan Lingkungan. Peraturan Menteri Pekerjaan Umum No. 26 Tahun 2008. Departemen Pekerjaan Umum. Jakarta.

RI (Republik Indonesia). Undang - Undang No. 24 Tahun 2007 Tentang Penanggulangan Bencana. Sekretariat Negara. Jakarta.

Xin, Jing., \& Huang, Chongfu. (2013). Fire risk analysis of residential buildings based on scenario clusters and its application in fire risk management. Fire Safety Journal $62,72-78$.

Yanuar, Fiska (2012). Pemanfaatan Teknik Penginderaan Jauh untuk Pemetaan Tingkat Kerawanan Kebakaran Permukiman, Jurnal Geo Image, 1 (1), 611. 